\title{
GRL/NASDA airborne SAR (Pi-SAR) observations of sea ice in the Sea of Okhotsk
}

\author{
Takeshi Matsuoka, ${ }^{1 *}$ Seino Uratsuka, ${ }^{1}$ Makoto Satake, ${ }^{1}$ Tatsuharu Kobayashi, ${ }^{1}$ \\ Akitsugu Nadai, ${ }^{1}$ Toshihiko Umehara, ${ }^{1}$ Hideo Maeno, ${ }^{1}$ Hiroyuki Wakabayashi, ${ }^{2}$ \\ Kazuki Nakamura, ${ }^{3}$ Fuminiko Nishio ${ }^{3}$ \\ ${ }^{1}$ Applied Research and Standards Division, Communications Research Laboratory, Nukui-Kitamchi 4-2-1, Koganei-shi, Tokyo 184-8795, Japan \\ ${ }^{2}$ Earth Observation Research Center, National Space Development Agency of Japan, Roppongi 1-9-9, Minato-ku, Tokyo 106-0032, Japan \\ ${ }^{3}$ Center for Earth Remote Sensing, Chiba University, 1-33 Yayoi-chou, Inage-ku, Chiba 263-8522, Japan
}

\begin{abstract}
Multi-frequency, multi-polarization airborne synthetic aperture radar (SAR) observations of sea ice in the southern Sea of Okhotsk were carried out in February 1999 in conjunction with RADARSAT SAR observations. The final goal of this study is to clarify the backscattering characteristics and to understand the scattering mechanisms of sea ice in the Sea of Okhotsk by using microwave multiparametric SAR. The airborne SAR (Pi-SAR) has two frequencies (X-and L-band) and multi-polarization ( $\mathrm{HH}, \mathrm{VV}$, $\mathrm{HV}, \mathrm{VH}$ ) with $1.5 \mathrm{~m}$ (X-band) and $3.0 \mathrm{~m}$ (L-band) resolution. It was developed by the Communications Research Laboratory (X-band) and the National Space Development Agency of Japan (L-band). We show the frequency dependence and polarization properties of radar backscattering from sea ice. We find that it is possible to distinguish ice types by comparing backscattering from sea ice in the X- and L-bands. Investigation of the polarization characteristics at X-band was very useful for detecting the thin-ice area (e.g. nilas and gray ice).
\end{abstract}

\section{INTRODUGTION}

The presence or absence of sea ice in the ocean is clearly an important factor in overall heat exchange at high latitudes. The Sea of Okhotsk represents one of the southern limits for seasonal sea ice in the Northern Hemisphere. Calculation results of general circulation models have shown that global warming significantly affects the extent of sea ice in the Sea of Okhotsk (Noda and others, 1996). Also, changes in the extent of sea ice influence not only the atmospheric response around the Sea of Okhotsk, but also the downstream towards North America (Honda and others, 1999). Monitoring the temporal and spatial distribution of sea ice in the Sea of Okhotsk is very important for detecting global climate change.

Microwave remote sensing of sea ice by space-borne or airborne synthetic aperture radar (SAR) is a technique that provides high spatial resolution and all-weather images independent of solar illumination. To date, operational SARs with a single frequency and a single polarization (e.g. ERS-1, -2, JERS-1, RADARSAT) have provided information regarding the horizontal distribution of sea ice. However, ascertaining volumetric distributions and distinguishing different types of ice by using single-frequency, single-polarization SAR images remains difficult. Observations of Arctic sea ice pro-

\footnotetext{
* Present address: Okinawa Subtropical Environment Remote-Sensing Center, Communications Research Laboratory, Daigusukubaru 829-3, Kuba, Nakagusuku, Nakagami, Okinawa 901-2401, Japan.
}

vided by multi-frequency polarimetric SAR (NASA, DC-8 aircraft) have indicated that combinations of frequency and polarization enhance our ability to distinguish between ice of different properties (Drinkwater and others, 1991).

In this paper, we report recent observations of seasonal sea ice in the Sea of Okhotsk made possible by a new dualfrequency multi-polarization airborne SAR. We also show some of the first examples of multi-frequency, multi-polarization SAR data for this sea ice. The frequency and polarization dependence of SAR backscattering from sea ice is discussed.

\section{OBSERVATIONS}

\section{SAR}

Dual-frequency, polarimetric airborne SAR has been named Pi-SAR (polarimetry in the X- and L-band, and interferometry in the $\mathrm{X}$-band). It was developed by the Communications Research Laboratory (CRL/X-band) and the National Space Development Agency of Japan (NASDA/L-band). In the Pi-SAR, the frequencies for the $\mathrm{X}$ - and L-bands are $9.55 \mathrm{GHz}(3.14 \mathrm{~cm}$ wavelength) and $1.27 \mathrm{GHz}$ ( $23.5 \mathrm{~cm}$ wavelength). The spatial resolutions are $1.5 \mathrm{~m}$ for the $\mathrm{X}$-, and $3.0 \mathrm{~m}$ for the L-band. The radar systems are mounted on an aircraft (Gulfstream II), and the image data are taken at a flight speed of about $200 \mathrm{~m} \mathrm{~s}^{-1}$ at altitudes of $6000-12000 \mathrm{~m}$. The two frequency systems operate simultaneously. The ground-range swath is approximately $15 \mathrm{~km}$, and typical incidence angles are $20-60^{\circ}$ (Kobayashi and others, 1998). The radiometric calibration is better than $\pm 1.5 \mathrm{~dB}$ in backscattering coefficient. In this paper, we focus 

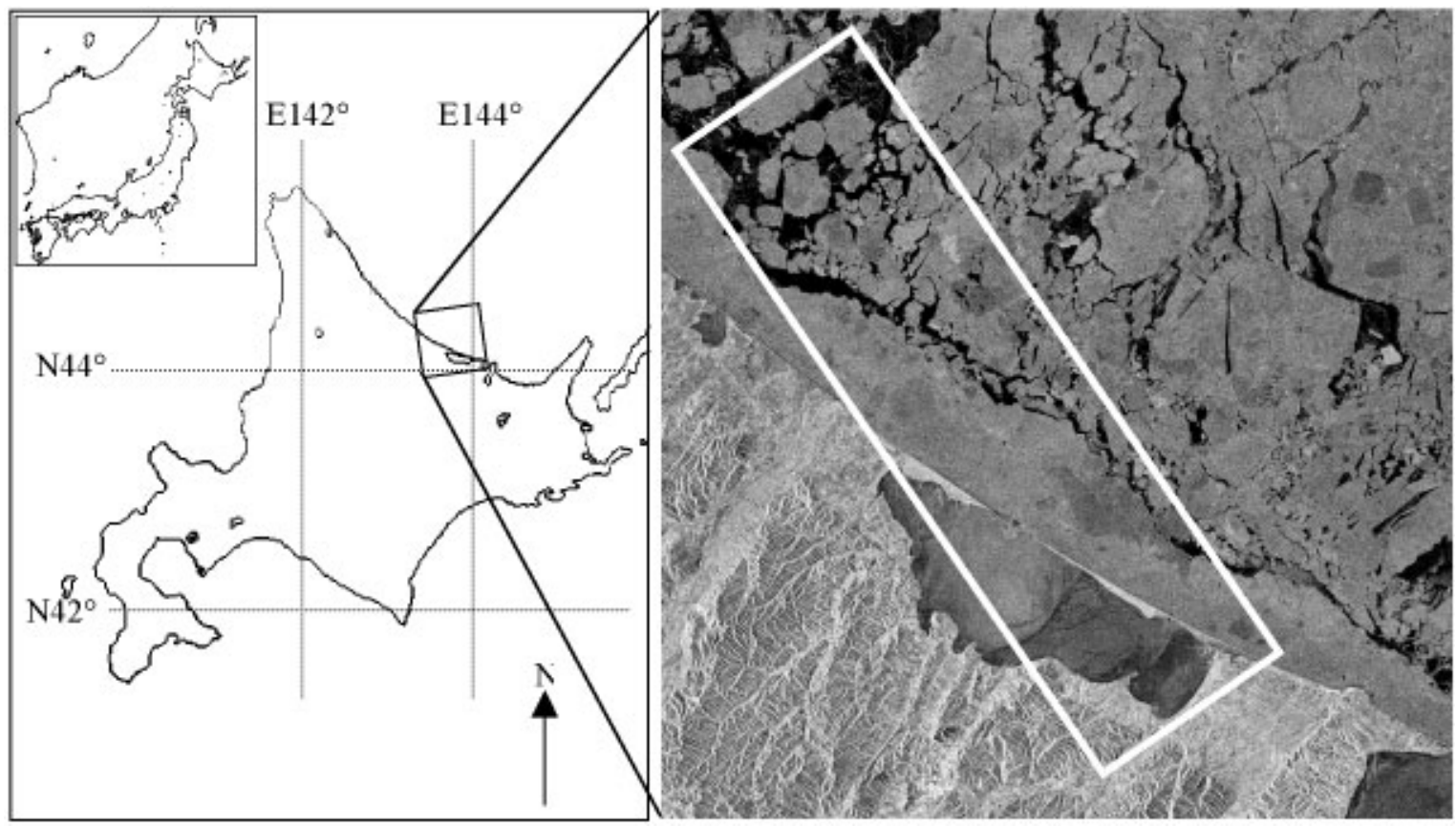

Fig. 1. Map of test site and RADARSAT SAR (C-HH, incidence angle of 23-25 ) image acquired on 23 February 1999.

on the backscattering magnitude data. The phase calibration is still ongoing; polarimetric analysis including the phase dependence of backscattering from sea ice is not discussed.

\section{Test site}

The Pi-SAR observations of sea ice in the Sea of Okhotsk were carried out near the northeastern coast of Hokkaido,
Japan. The data were acquired on 23 and 24 February 1999, in conjunction with RADARSAT SAR observations (Cband; $5.3 \mathrm{GHz}, \mathrm{HH}$ polarization, spatial resolution about $30 \mathrm{~m}$ ). In situ truth data of the floating sea ice were not obtained because it is difficult to access the thin, unstable sea ice. However, photographs of the sea ice from the aircraft were taken simultaneously during the Pi-SAR observations when weather permitted.
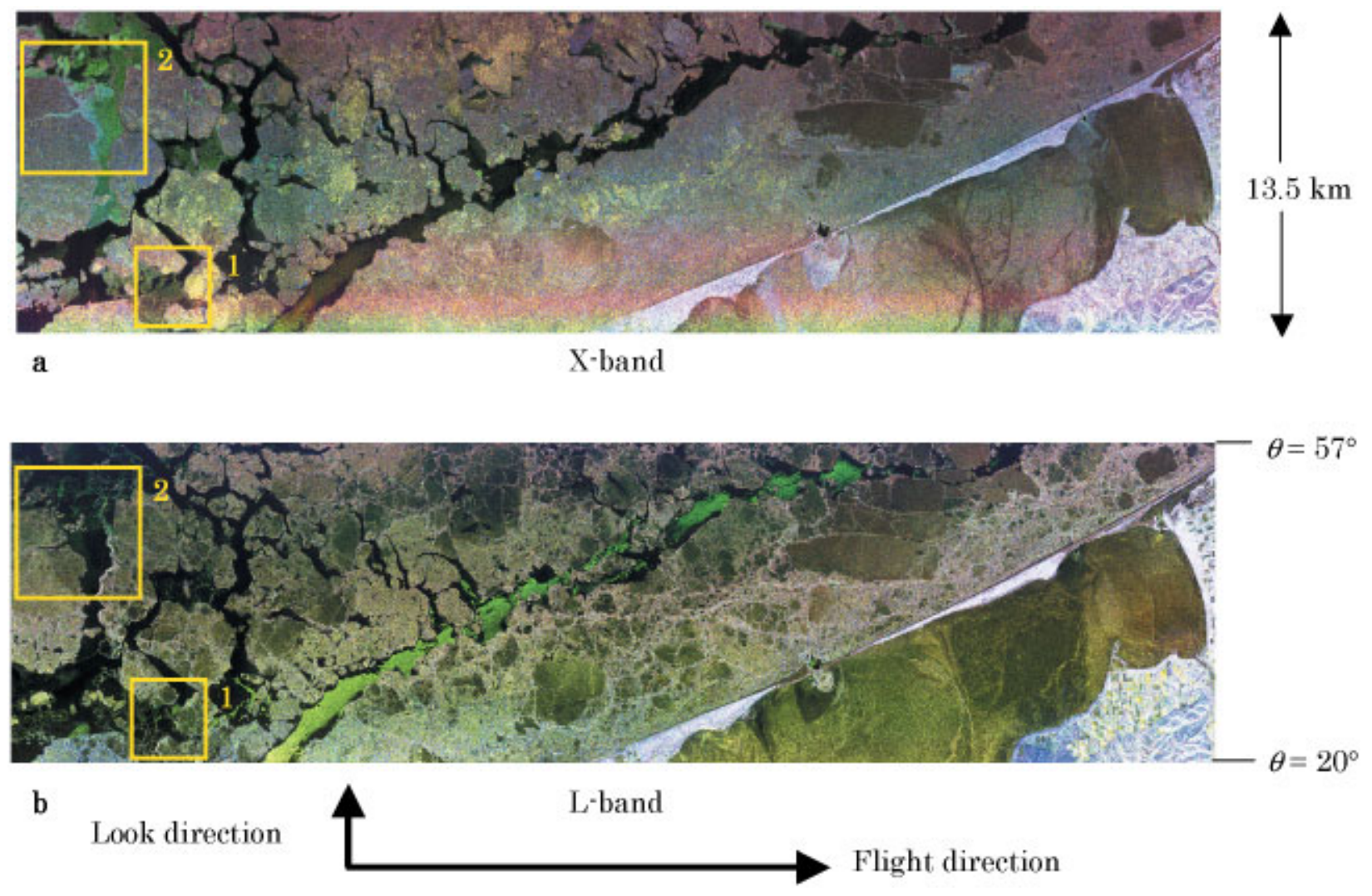

Fig. 2. Pi-SAR images of (a) X-band, and (b) L-band acquired on 23 February 1999, as color composites of HH (red), VV ( green) and $H V$ (blue) channels. Swath width is $13.5 \mathrm{~km}$ and azimuth distance is $50.0 \mathrm{~km}$. 


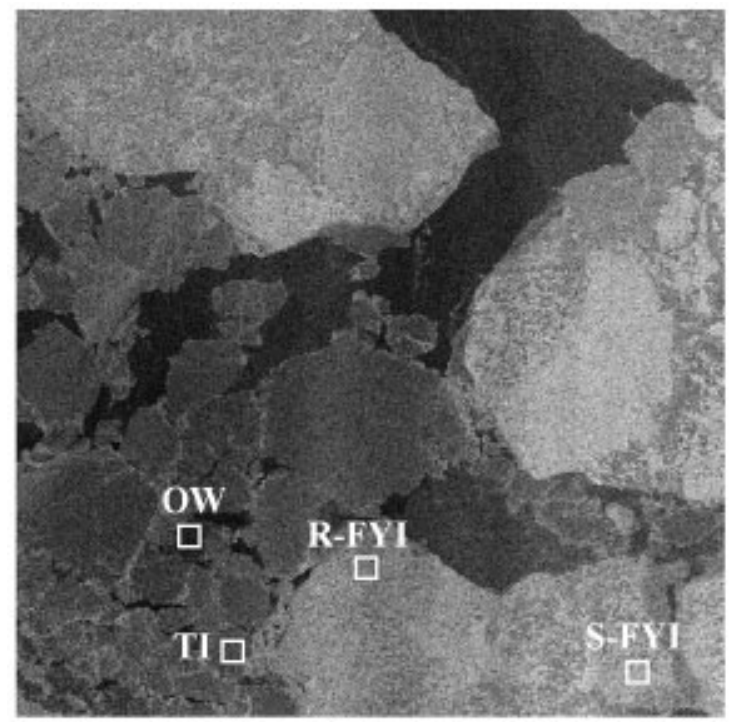

a pi-SAR, X-band $(9.55 \mathrm{GHz}) \mathrm{HH}$

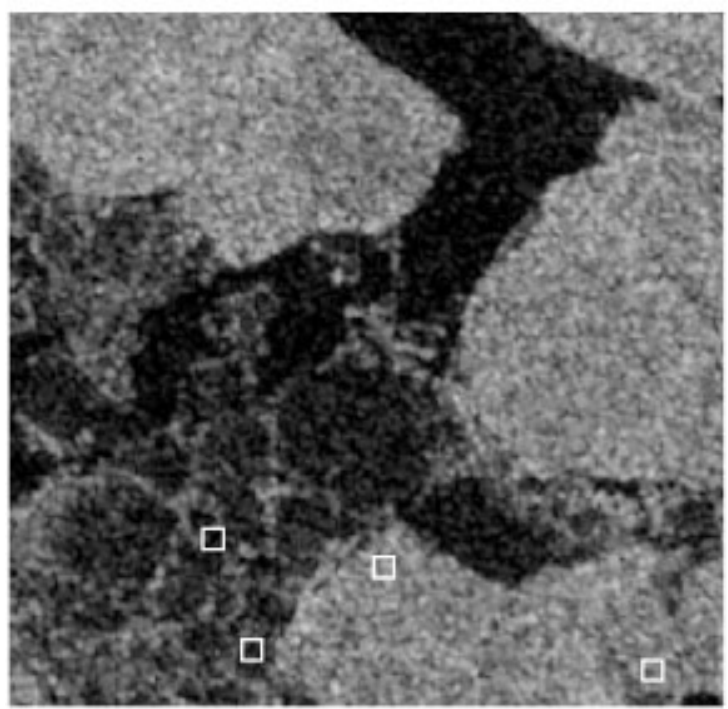

c RADARSAT, C-band $(5.3 \mathrm{GHz}) \mathrm{HH}$

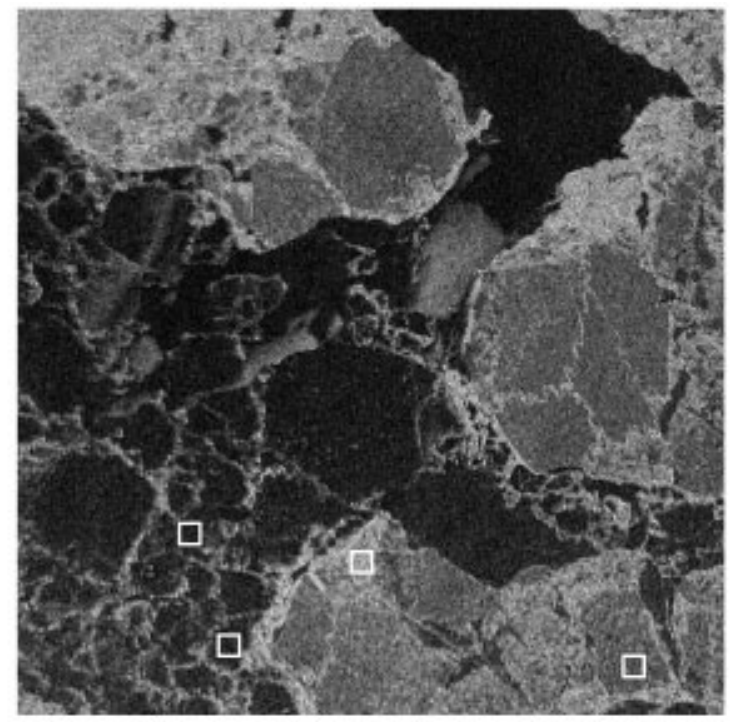

b pi-SAR, L-band $(1.27 \mathrm{GHz}) \mathrm{HH}$
Fig. 3. Extended Pi-SAR images of square 1 in Figure 2 in (a) L-band $H H$, and (b) X-band HH. Incidence angles of the marked areas are 23-25. (c) RADARSAT image of the same area. Each image is $3 \mathrm{~km} \times 3 \mathrm{~km}$.
Figure 1 shows a map of the test site and the RADARSAT SAR image acquired on 23 February 1999. The SAR image covers about $53 \mathrm{~km} \times 53 \mathrm{~km}$. The radar incidence angle to the area is between $23^{\circ}$ for the left side and $25^{\circ}$ for the right side. More than $90 \%$ of the sea in the image was covered with sea ice at the time of the observation. The large seawater lake (with salinity of $>30 \mathrm{ppt}$ (parts per thousand)) covered with sea ice near the coast in the lower center of the image is Lake Saroma. The white rectangle represents the Pi-SAR observation area, shown in Figure 2.

Figure $2 \mathrm{a}$ and $\mathrm{b}$ show the Pi-SAR browse images of the X- and L-bands, acquired on 23 February 1999, as color composites of the $\mathrm{HH}$ (red), $\mathrm{VV}$ (green) and $\mathrm{HV}$ (blue) channels. The swath width is $13.5 \mathrm{~km}$ and the incidence angle is between $20^{\circ}$ (near range) and $57^{\circ}$ (far range). Lake Saroma is on the right in the image. These browse images were processed for the large area with low resolution $(10 \mathrm{~m})$; some nominal radiometric contribution has not been removed in the processing of range direction. In the following section, we used well-calibrated detailed images to describe the backscattering properties of sea ice.

\section{RESULTS AND DISGUSSION}

\section{Frequency dependence}

We show the frequency dependence of SAR backscattering using the Pi-SAR and RADARSAT data with specific incidence angle $\left(24^{\circ} \pm 1^{\circ}\right)$ and polarization $(\mathrm{HH})$. Figure $3 \mathrm{a}$ and $b$ show detailed images of square 1 in Figure 2. Figure $3 \mathrm{a}$ corresponds to the image in Figure $2 \mathrm{a}$, and Figure $3 \mathrm{~b}$ to that in Figure $2 \mathrm{~b}$. The image covers $3 \mathrm{~km} \times 3 \mathrm{~km}$, and the incidence angle is $23-34^{\circ}$. Figure $3 \mathrm{c}$ shows a RADARSAT image (standard mode; Sl) of the same region. From the photographs of the sea ice taken from the aircraft, and from our knowledge of the dielectric properties and typical surface conditions of sea ice, we reach the following empirical conclusions about the area types. There are four basic types. The first is open water (OW) shown by dark areas (weak backscattering) in all three frequency images. When the water was calm, the backscattering coefficients almost reached the noise level due to the specular reflection of the microwaves. The second type is thin ice (TI), such as nilas 
Table 1. Frequency dependence of backscattering coefficients $(d B)$ from sea and various sea-ice surfaces at incidence angles of 23-25. Mean values of each marked square in Figure $3 a-c$ are shown

\begin{tabular}{lcccc}
\hline Band & OW & TI & S-FYI & R-FYI \\
\hline L (Pi-SAR) & -31.0 & -28.5 & -21.8 & -11.7 \\
C (RADARSAT) & -26.0 & -23.5 & -13.0 & -11.3 \\
X (Pi-SAR) & -30.4 & -21.0 & -8.7 & -14.4 \\
\hline
\end{tabular}

and gray ice, shown by dark areas similar to the area of open water in the low-frequency image, but distinguishable in the high-frequency (X-band) image. The third type is smooth surface first-year ice (S-FYI) shown as a bright area in the high-frequency image, and as a slightly bright, rounded area surrounded by bright curved lines in the low-frequency (Lband) image. The last type is rough surface first-year ice (R-FYI) visible as bright areas in all three images.

The backscattering coefficients of these surfaces using frequency as a parameter, at incidence angles of $23-25^{\circ}$,

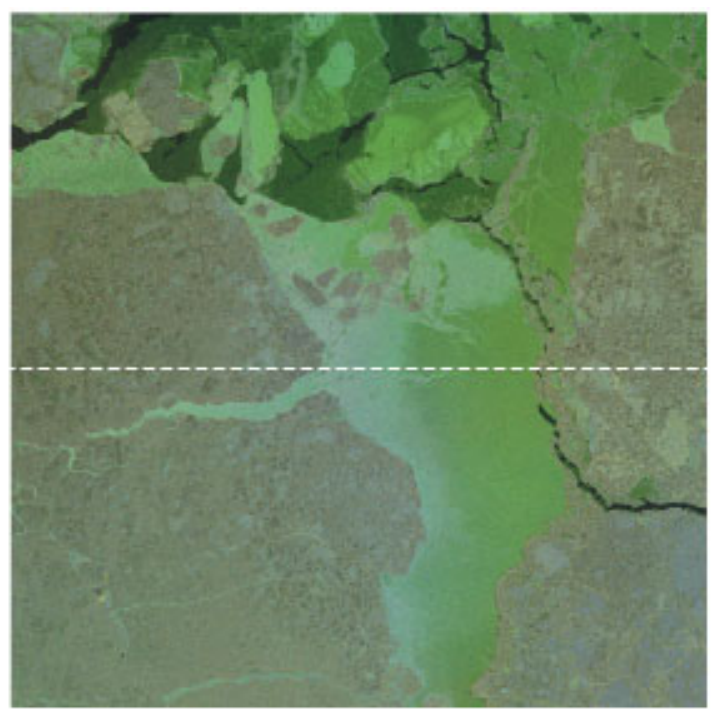

a

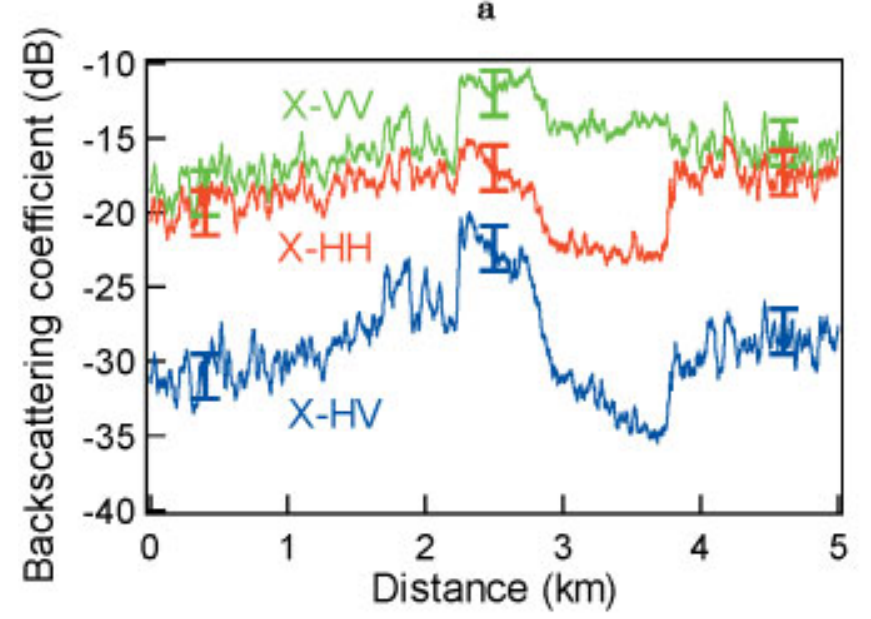

c are shown in Table 1 . The backscattering coefficients are the mean values of the marked areas in Figure $3 \mathrm{a}-\mathrm{c}$. The incidence angles of the marked area were $23-25^{\circ}$ in Figure $3 \mathrm{a}$ and $b$; the incidence-angle dependence on the backscattering coefficient was negligible. There is a difference of approximately $10 \mathrm{~dB}$ between the open water and the thin ice in the X-band, and of approximately $3 \mathrm{~dB}$ in the L- and $\mathrm{C}$-bands. The $\mathrm{X}$-band is very effective in detecting thin-ice zones, whereas the L-band discriminates well between smooth and rough surface first-year ice.

\section{Polarization characteristics of thin ice}

Figure 4a shows an image of the Pi-SAR X-band, and Figure $4 \mathrm{~b}$ an image of the L-band, as color composites of the $\mathrm{HH}$ (red), VV (green) and HV (blue) channels. The images are detailed ones of square 2 in Figure 2, and represent an area of $5 \mathrm{~km} \times 5 \mathrm{~km}$. There was a large difference between the backscattering coefficients in the X-and L-bands near the center of the image. Photographs of this area from the aircraft lead us to conclude that this area comprised bare surface thin ice such as nilas and gray ice surrounded by snow-covered firstyear ice. Figure 4c shows a profile of the X-band, and Figure

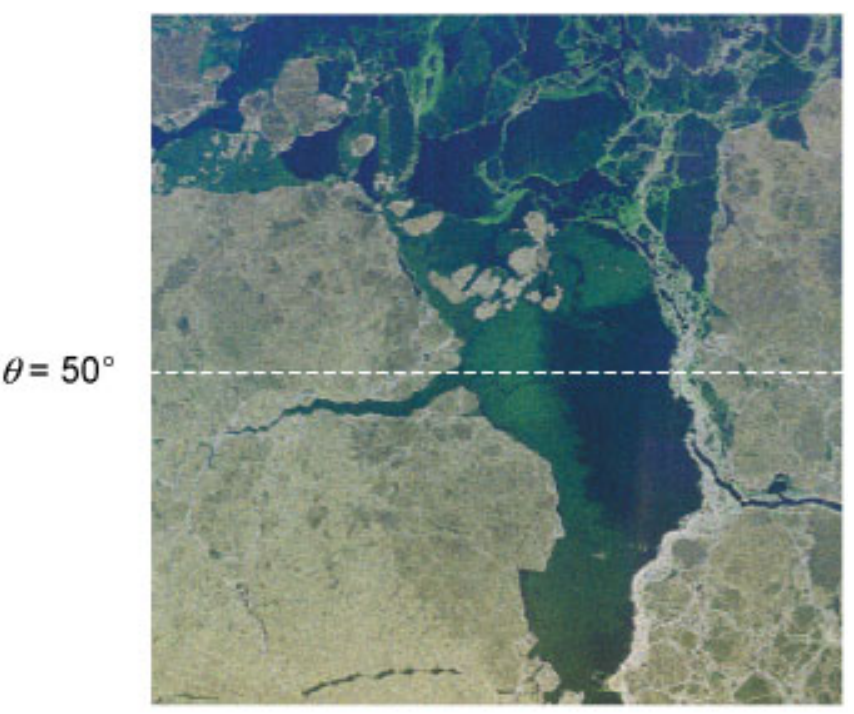

b

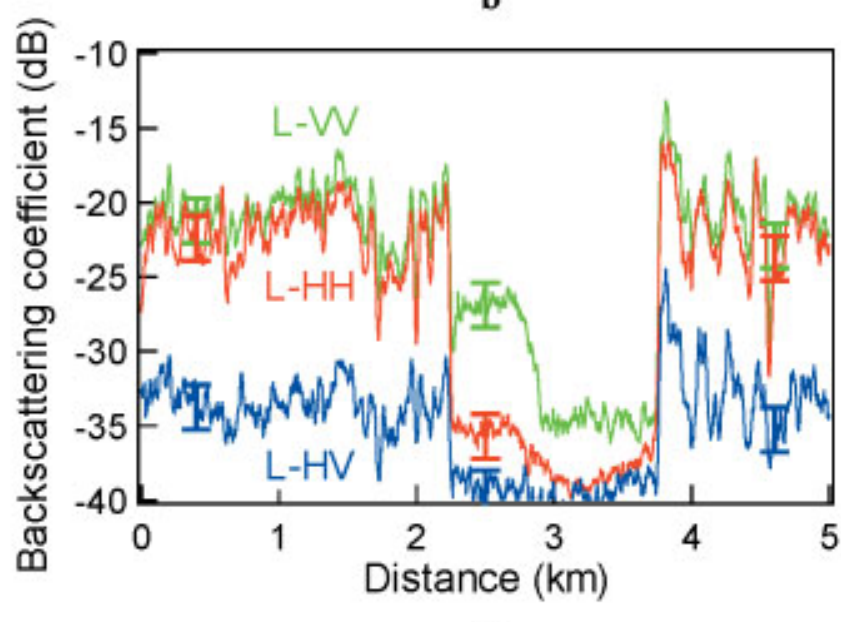

d

Fig. 4. Images of Pi-SAR ( $a$ ) in the X-band, and ( $b$ ) in the L-band, as color composites of $H H$ (red), VV (green) and HV (blue). Images correspond to square 2 in Figure 2 and cover $5 \mathrm{~km} \times 5 \mathrm{~km}$. (c,d) Profiles of backscattering coefficient of dashed lines (incidence angle of $\left.50^{\circ}\right)$ in $(a)$ and $(b)$, respectively, with polarization as parameter. The error bars are shown only at three distance points. 
$4 \mathrm{~d}$ a profile of the L-band, backscattering coefficients at an incidence angle of $50^{\circ}$ using polarization as a parameter. Each value in the profile was an averaged value of 400 and 100 pixels $(25 \mathrm{~m} \times 25 \mathrm{~m})$ in the $\mathrm{X}$ - and L-band image, respectively. The standard deviation of the backscattering coefficient was around $\pm 1.5 \mathrm{~dB}$.

Figure 4c shows that the backscattering coefficient of the thin-ice area in $\mathrm{VV}$ polarization is $>8 \mathrm{~dB}$ greater than that in $\mathrm{HH}$ polarization (polarization ratio: $\mathrm{VV}$ / $\mathrm{HH}>8 \mathrm{~dB}$ ), and $20 \mathrm{~dB}$ larger than that in $\mathrm{HV}$ polarization in the X-band (3.4-3.7 km distance). By contrast, in Figure $4 \mathrm{~d}$, the backscattering coefficients of the thin-ice area are very low (almost noise level) in all three polarization states in the L-band. Surface scattering may be dominant in this area. First-order surface scattering model calculations suggest that VV backscatter should exceed $\mathrm{HH}$ backscatter for smooth surface at this incidence angle (Winebrenner and others, 1989). The corresponding mean $\mathrm{VV} / \mathrm{HH}$ ratios at each frequency increase as the standard deviation of the surface height decreases and as the ice salinity and permittivity increase. These results suggest that the observed sea ice (3.4-3.7 km distance) was the thin ice having smoother surface and higher salinity than the surrounding first-year ice.

At distances of $2.5-3.0 \mathrm{~km}$ in Figure $4 \mathrm{c}$, the backscattering coefficients of the cross-polarization $\mathrm{HV}$ of the thin-ice area were larger than those of the first-year ice area in the X-band. As the air temperature was higher than $-10^{\circ} \mathrm{C}$ in the SAR observations, there was no multiple scattering caused by salt flowers on the sea-ice surface. This suggests that volume scattering and multiple scattering from the thin-sea-ice bodies cause large HV backscattering. However, at the typical salinity of thin sea ice, the dielectric constant is large (Ulaby and others, 1986). Thus, the penetration depth in the ice in the $\mathrm{X}$-band is very small $(<1 \mathrm{~cm})$, and the surface scattering appears to be the dominant cause of the backscattering mechanism. It is possible that there was thin ice with low salinity (several ppt) caused by the desalination of upper-level ice, which is subject to daily temperature changes. Model calculations for lowsalinity ice and brine characteristics like these will be carried out in the near future.

\section{CONGLUSIONS}

Dual-frequency multi-polarization airborne SAR (Pi-SAR) observations of sea ice in the Sea of Okhotsk were carried out in conjunction with RADARSAT SAR observations in February 1999.

Using the Pi-SAR (L- and X-band $\mathrm{HH}$ ) and RADARSAT (C-band $\mathrm{HH}$ ) data, the frequency dependence of the backscattering coefficient showed that the X-band is very useful for detecting thin-ice areas such as those of nilas and gray ice. L-band data are useful for discriminating between smooth and rough surface first-year ice.

Interesting differences were observed between the backscattering coefficients of $\mathrm{VV}$ and $\mathrm{HH}$ from the thin-ice zone in the X-band. The polarization ratio $(\mathrm{VV} / \mathrm{HH})$ was $>8 \mathrm{~dB}$. Also in the X-band $\mathrm{HV}$, the backscattering coefficient from the thin-ice area was very small. These results suggest that surface scattering was the dominant mechanism, and the observed sea ice was the thin ice having smoother surface and higher salinity than the surrounding first-year ice.

The observations are difficult to explain because of the complexity and variability of parameters that determine backscattering from sea ice. More detailed results and quantitative discussions with scattering models are required.

\section{REFERENGES}

Drinkwater, M. R., R. Kwok, D. P. Winebrenner and E. Rignot. 1991. Multifrequency polarimetric synthetic aperture radar observations of sea ice. 7. Geophys. Res., 96(C11), 20,679-20,698.

Honda, M., K. Yamazaki, H. Nakamura and K. Takeuchi. 1999. Dynamic and thermodynamic characteristics of atmospheric response to anomalous seaice extent in the Sea of Okhotsk. F. Climate, 12(12), 3347-3358.

Kobayashi, T., M. Satake, H. Masuko, T. Manabe and M. Shimada. 1998. CRL/NASDA airborne dual-frequency polarimetric interferometric SAR. Proc. European Remote Sensing, 3497(2), 2-12.

Noda, A., S. Nakagawa, T. Motoi, S. Yukimoto and T. Tokioka. 1996. Global warming induced by $\mathrm{CO}_{2}$ and the Okhotsk Sea. 7. Remote Sensing Soc. Jpn, 16(2), 3-13.

Ulaby, F. T., R. K. Moore and A. K. Fung. 1986. Microwave remote sensing, active and passive. Vol. 3. From theory to applications. Reading, MA, Addison-Wesley Publishing Co.

Winebrenner, D.P., L. Tsang, B. Wen and R. West. 1989. Sea-ice characterization measurements needed for testing of mcrowave remote sensing models. IEEE 7. Oceanic Eng., OE-, 14(2), 149-158. 